\title{
Feasibility Study of While-drilling Data Transmission Technology Based on Radio Frequency Identification
}

\author{
Wei-Ning Ni ${ }^{*}$, Ji-Bo Li, Shan-Guo Li and Wei Zhang
}

Research Institute of Petroleum Engineering Technology, SINOPEC, Beijing 100101, China

\begin{abstract}
Downhole data transmission methods based on mud-pulse and low-frequency electromagnetic waves can't satisfy the need of large amount and high speed data uploading during drilling. In this paper, a novel data transmission technique based on releasing RFID tags by LWD tools is designed and validated. As the memory and transmission media, RFID tags are pre-mounted tactfully in cavities of the downhole releasing tool which can transmits/write LWD data to these tags. By releasing regularly or irregularly into the annulus fluids, RFID tags can be carried to the surface by mud circulation. To finish data transportation function, LWD data can be read out on the surface. Wireless charging high capacity (1Mbits) RFID tags are designed, which contains microprocessor and memory, to expand the storage capacity of RFID tags. The power supply for microprocessor and memory in the tag is electromagnetic waves from RF Reader/Writer module. The equivalent data transmission speed of this system can be up to $278 \mathrm{bit} / \mathrm{s}$ ( $1 \mathrm{tag} / \mathrm{h}$ is assumed), which is more much faster than the traditional mud pulser $(<10 \mathrm{bit} / \mathrm{s})$.
\end{abstract}

Keywords: Annulus, LWD, memory, mud-pulse, RFID.

\section{INTRODUCTION}

Logging while drilling (LWD) tools have been widely used in the unconventional gas and oil resources development $[1,2]$. More and more engineering and geological data are collected downhole during drilling operation. Downhole data transmission method and tool while drilling is still big bottleneck for real-time applications. A variety of wireless logging data transmission techniques have been developed, such as: mud-pulse, low-frequency electromagnetic wave (EM), acoustic transmission [3-6]. In addition, intelligent drill pipe is also one of the solutions. Currently, among above methods, mud-pulse is the most widely used; and the second is low frequency electromagnetic wave. Other methods are rarely used in industrial application because of cost and safety reasons [7]. However, the data transmission speed of mud-pulse and EM wave is too low ( $<10 \mathrm{bit} / \mathrm{s})$ to satisfy the requirement of more and more parameters transmission. A novel while-drilling data transmission technique based on RFID (Radio Frequency Identification) is proposed and researched in this paper.

\section{RFID SYSTEM PRINCIPLE}

A typical RFID system includes the electronic tag, Reader and remote computer for data processing, as shown in Fig. (1). An electronic tag is similar to a radio frequency card with ability to be read, write and encrypt for communication. Electronic tag is composed of antenna, matching network, relay module, central controller, communication algorithm module, memory, etc. The RFID reader is composed of

\footnotetext{
*Address correspondence to this author at the Research Institute of Petroleum Engineering Technology, SINOPEC, Beijing 100101, China; Tel: +86-10-84988622; Fax: +86-10-84988725;

E-mail: niwn.sripe@sinopec.com
}

antenna, wireless control module and interface circuit. The reader transmits modulated signal to electronic tag, which receives and demodulates the signal and responds back to the reader. Finally, signals are sent to a computer or other data processing equipment.

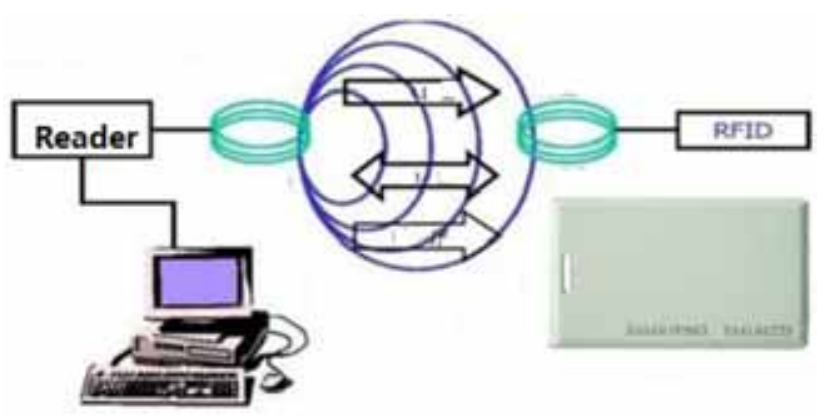

Fig. (1). Principle of RFID system.

The recent years, the potential applications of RFID technology began to be recognized, such as Weatherford's the RFID operated frac sleeves and Drilling-Reamer [8-10]. Operation principle of the later is as follows. Firstly, instruction command data are written to a RFID tag. Secondly, drop the RFID tag into wellbore to reach the downhole tool section with the help of mud circulation. RFID reader installed on the Drilling-Reamer read the instruction within RFID tag. Then Drilling Reamer change is open or close status according to the instruction contents. These techniques focus on data transmission from surface to downhole, cannot realize data transmission from downhole to surface.

\section{RFID DRILLING DATA TRANSMISSION}

A novel RFID system for data transmission from downhole to surface is designed based on RFID, which has expe- 
rienced continuous improvement, research and testing. The key technologies, such as the RFID with big memory and the downhole reader, will be introduced below.

\subsection{Releasing RFID Tags}

The mode of RFID tags delivery is shown in Fig. (2). The releasing tool is a part of BHA, it can be connected with other LWD tools through signal cables to gather data surveyed by these formation evaluation sensors. Drilling releasing tool has a cavity, which provided the space for one or many RFID tags to be located in. The reader on the release tool transmits (write) the gathered data to the RFID Tags by wireless. After data writing, a RFID tag is released into the annulus at regular time, which will follow the mud circulation to the surface.

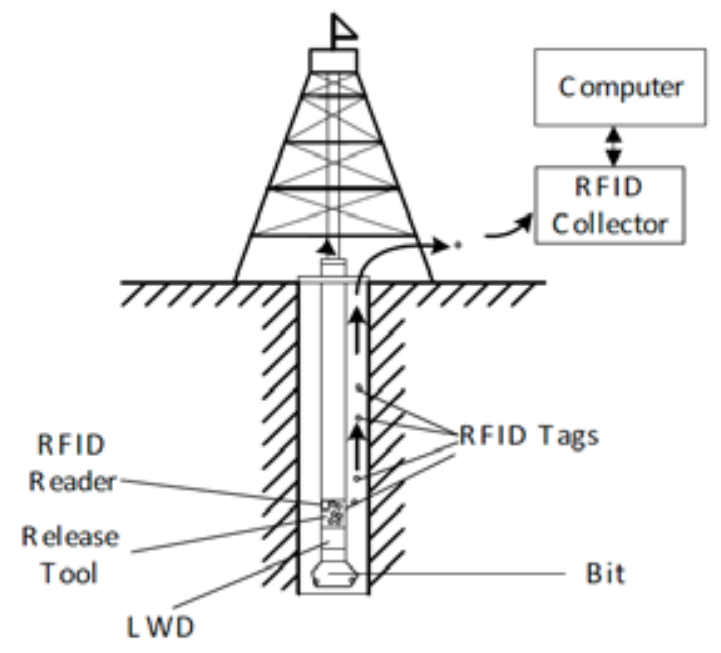

Fig. (2). RFID tags delivery mode.

The reader on the surface can read data out of the RFID tag. Because the RFID tag does not have to pass through the bit nozzle, the tag size can be fully optimized, and data transmission is more efficient. The delivering mode only has some delay time effect caused by mud circulation time.

\subsection{Releasing Tool Structure}

As shown in Fig. (3), the releasing tool is composed of several modules, such as receiving antenna, storage cavity, controlling module, transmitting antenna and releasing actuator. Receiving antenna can receive command data in RFID tags from surface. Storage cavity is used to store RFID tags. Printed circuit board assembly (PCBA) is mounted on control module for avoiding shocking damage. Transmitting antenna is responsible to transmit data to RFID tag. The release of RFID tags from the storage cavity is under control of releasing actuator. Release force comes from the differential pressure between the inside and outside of drill pipe.

The working modes for tags releasing is as follows: When there is appointed time, the PCBA in the control module will transmit the logging data to the specified RFID tags. The speed of this data transmission is very fast, which can be up to $10 \mathrm{k} \mathrm{bit/s}$. The release actuator release RFID tag from storage cavity when all data transmission to RFID tag is finished. The releasing process is realized through opening of a solenoid valve. When the valve is open, storage cavity will be connected with outside borehole annulus. Finally, the RFID tag which is filled with the logging data will be pushed into the circulating mud in the borehole annulus.

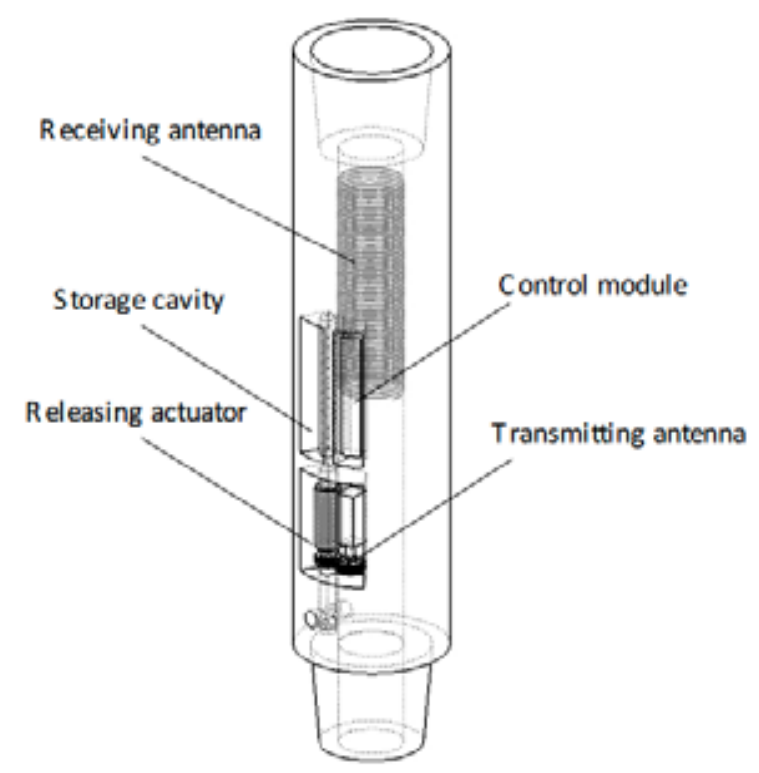

Fig. (3). Diagram of releasing tool.

\subsection{Wireless Charging and High Capacity RFID Tag}

Most traditional RFID tags are made in the form of plat card, as shown in Fig. (4). The card size is mainly determined by antenna's coil size. RFID tags are capable of wireless charging. When a RFID tag works, it's charged in a wireless way first, and then its internal circuits start to complete the identity recognition function. But due to the traditional application requirements, the data storage ability of these traditional RFID tags is relatively small. The maximum memory size is only $1 \mathrm{~K}$ bits, which cannot meet requirement of most imaging logging tools. Therefore, external physical memories are needed to extend the storage space.

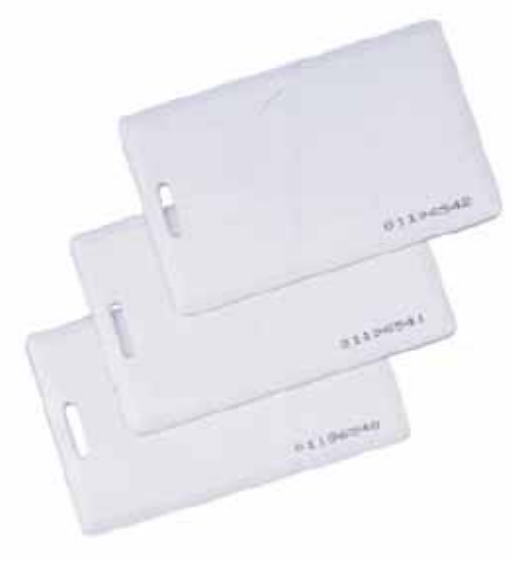

Fig. (4). Traditional RFID tags.

RFID tag for drilling transmission needs to work under hostile conditionals of borehole bottom. Considering survival requirements, such as high pressure and high temperature, it's not possible to use a big battery because it is also diffi- 
cult to reuse. Therefore, there is a requirement for a different kind of power supply to drive the microprocessor and memory efficiently. In this paper, a novel wireless charging technique via the RF signal is proposed. The structure of high storage capacity (1M bit) RFID tag with functions of wireless charging is as shown in Fig. (5).

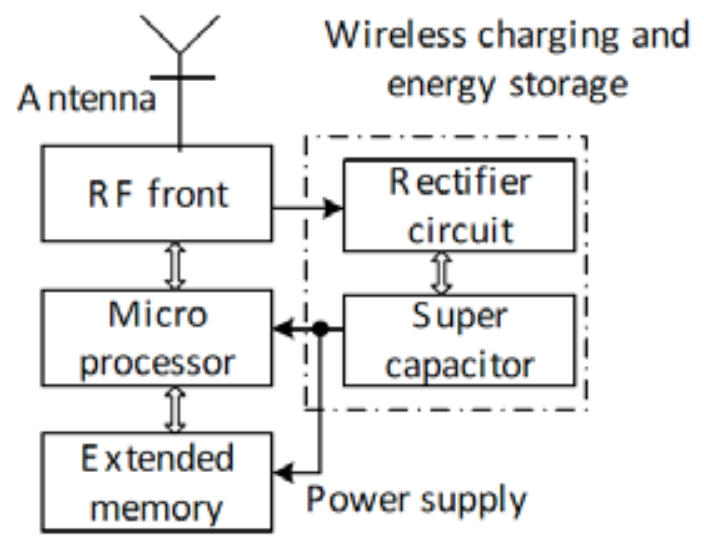

Fig. (5). Block diagram of high capacity RFID tag with wireless charging.

Wireless charging technique is derived from wireless power transmission technology. Wireless charging, also known as inductive charging or the contactless inductive charging, is based on near field induction principle, or namely inductive coupling. The power supply equipment (charger) transmits energy to electric device, the device using the received energy to charge the battery or capacitor for its own operation. Because energy is transmitted from charger to electric device by means of inductive coupling without wire connection, the charger and electric device can be made without exposed conductive contact.

Because of the rigorous space limitation of LWD tools, antenna is the most critical component of whole system. As passive RFID tag mainly works in a frequency range from the hundreds $\mathrm{KHz}$ to tens of $\mathrm{MHz}$, antenna works mainly in the way of coil inductance coupling. From Equation 1, it can be known that, under the same condition, more coil's turns will result in a stronger magnetic field. The smaller the radius of the coil is, the weaker the magnetic field is. Therefore, under the constraint of a small size, the magnetic field strength can be improved by increasing the number of turns as more as possible.

$H=\frac{I \cdot N \cdot R^{2}}{2\left(R^{2}+X^{2}\right)^{3}}$

Where $\mathrm{H}$ is the magnetic field strength; $\mathrm{I}$ is current intensity; $\mathrm{N}$ is the number of coil' turns; $\mathrm{R}$ is the antenna radius; $\mathrm{X}$ is the effective distance.

In order to get the highest emission efficiency, resonance frequency and working frequency of circuit must be the same, as equation 2 shows

$f=\frac{1}{2 \pi \sqrt{L C}}$

Where $f$ is the work frequency, $\mathrm{C}$ is the RFID tag's capacitance, $\mathrm{L}$ is the antenna's inductance.
$\mathrm{L}=\frac{\left(0.01 \times \mathrm{D} \times N^{2}\right)}{\left(\frac{l}{D}+0.44\right)}$

Where $\mathrm{L}$ is the coil inductance, $\mathrm{D}$ is the coil diameter, $\mathrm{N}$ is the number of coil's turns, and $l$ is the coil length.

From equations 2 and 3, it can be concluded that the number of turns of coil must be in a constraint range to make sure that $\mathrm{L}$ is in the range of resonant frequency. Combining equations 1,2 and 3, coil turns of 100 and antenna diameter of $8 \mathrm{~mm}$ are selected for a $13.56 \mathrm{MHz}$, Coil turns of 100 and antenna diameter of $2 \mathrm{~mm}$ are selected for a $134 \mathrm{KHz}$ RFID tags design. The tag is $16 \mathrm{~mm}$ long by $17 \mathrm{~mm}$ wide, the height of it is $3 \mathrm{~mm}$. Epoxy resin was used for packaging the RFID tag. According to the cycle time of mud and the well depth, the RFID tag from the bottom to the ground takes about from half an hour to one hour.

\section{RFID READER CIRCUIT}

PCBA in control module is powered by a battery, which has to work for several hundred hours downhole. Therefore, low power and small size are the key features during PCBA designing. PCBA together with its functional block diagram are shown in Fig. (6). The PCBA's size is $40 \mathrm{~cm} * 4 \mathrm{~cm}$, whose power consumption is $15 \mathrm{~mW}$.

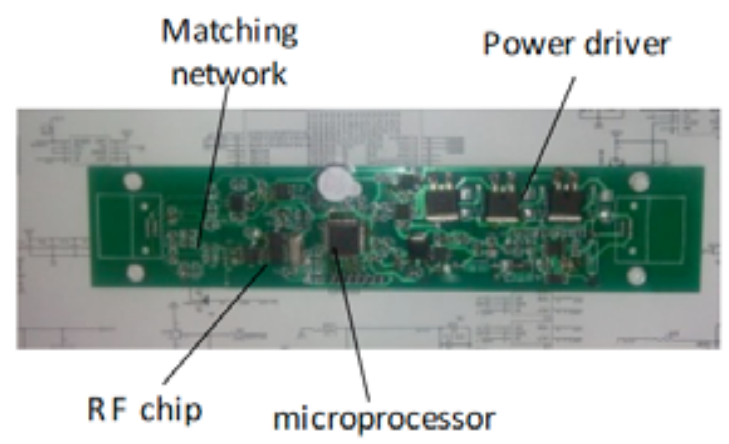

Fig. (6). Photo of PCBA.

A $28.8 \mathrm{~V}$ voltages battery pack is implemented with 8 high temperature lithium batteries in series. This battery pack can supply provide power to the RFID PCBA for a time of 200h continuously. Microprocessor controls transmitting and receiving of a radio frequency chip. The radio frequency chip modulates logging data on a carrier wave which will be transmitted by antenna later. RFID tag is charged by carrier wave signals, and then it is started. It detects and demodulates modulation signal, and receives gathered data. It takes about 10 minutes to complete the downloading $1 \mathrm{Mbit}$ data.

\section{EXPERIMENTAL RESULTS AND DISCUSSION}

All testing of PCBA, batteries, motor and data transmission process are completed on surface simulation environment. In addition, reliability tests, such as $70 \mathrm{MPa}$ pressure and $125^{\circ} \mathrm{C}$ temperature are done. It was validated that our RFID tag can survive and work well after above HT/HP tests. A 1Mbit RFID tag has been filled with logging data for 100 s by PCBA. Assuming that one 1Mbit RFID tag is released every one hour from downhole, a transmission speed equal to $1 \mathrm{Mbit} / \mathrm{h}$ or $278 \mathrm{bit} / \mathrm{s}$ can be achieved, which is much 
more faster than the traditional mud-pulser (<10bit/s). The testing results demonstrated the novel while-drilling data transmission system based on RFID is already of strong drilling information transmission ability, which also can meet the downhole reliability requirements.

\section{CONCLUSION}

While drilling data transmission from downhole to the surface based on RFID is completely feasible. This novel data transmission concept is different from all references; and the data transmission rate is also much faster than before methods. Differential pressure between insides and outsides of drill pipe is a good choice to push the micro RFID tag to the borehole annulus. As the key technique of whole transmission system, miniature high-capacity RFID tag will be optimized for data transmission rate improvements in the future. Focusing the releasing tool and the receiving system on the surface is the next step.

\section{CONFLICT OF INTEREST}

The authors confirm that this article content has no conflict of interest.

\section{ACKNOWLEDGEMENTS}

Declared none.

\section{REFERENCES}

[1] S. Paul, A.Z. Li, and O. Aaron, "LWD azimuthal laterolog resistivity logging in unconventional reservoirs”, In: Asia Pacific Drilling Technology Conference and Exhibition, TianJin, China, July 9$11,2012$.

[2] R. Nye, and D. D. Tommaso, "Well optimization using a LWD spectral azimuthal Gama ray tool in unconventional reservoirs", In: Offshore Mediterranean Conference and Exhibition, Ravenna, Italy, March 20-22, 2013

[3] C. Klotz, P. Bond, and I. Wasserman, "A new mud pulse telemetry system for enhanced MWD/LWD applications", In: Drilling Conference Orlando, U.S.A, March 4-6, 2008.

[4] A. Caruzo, R. Hutin, and S. Reyes, "Advanced design and execution techniques for delivering high data rate MWD telemetry for ultradeep wells", In: Arctic Technology Conference, Houston, USA, December 3-5, 2012.

[5] J. Schnitger, and J. Macpherson, "Signal attenuation for electromagnetic telemetry systems", In: Drilling Conference and Exhibition, Amsterdam, Netherlands, March 17-19, 2009.

[6] L. Gao, D. Finley, and W. Gardner, "Acoustic telemetry can deliver more real-time downhole data in underbalanced drilling operations", In: Drilling Conference, Miami, USA, February 21-23, 2006

[7] B. Siahaan, K. S. Bjorkevoll, and Jan. E, "Possibilities of using wired drill pipe telemetry during managed pressure", In: Drilling in Extended Reach Wells, Intelligent Energy Conference and Exhibition, Utrecht, Netherlands, April 1-3, 2014.

[8] J. Tough, J. Mason, and R. Biedermann, "Radio frequency identification of remotely operated horizontal frac", In: North American Unconventional Gas Conference and Exhibition, Woodlands, USA, June 14-16, 2011.

[9] D. Purkis, "Switching device for and a method of switching a downhole tool", U.S. Patent 20,110, 248,566, October 13, 2011

[10] D. Purkis, "Apparatus and method for downhole communication", U.S. Patent 20,120,146,806, June 14, 2012.

Received: October 16, 2014

Revised: February 27, 2015

Accepted: June 23, 2015

(C) Ni et al.; Licensee Bentham Open.

This is an open access article licensed under the terms of the Creative Commons Attribution Non-Commercial License (http://creativecommons.org/licenses/by-nc/3.0/) which permits unrestricted, non-commercial use, distribution and reproduction in any medium, provided the work is properly cited. 